\title{
Fermentation of calcium-fortified soya milk does not appear to enhance acute calcium absorption in osteopenic post-menopausal women
}

\author{
Anne Lise Tang Fook Cheung ${ }^{1}$, Gisela Wilcox ${ }^{1,2}$, Karen Z. Walker ${ }^{3}$, Nagendra P. Shah ${ }^{1}$, Boyd Strauss ${ }^{2}$, \\ John F. Ashton ${ }^{4}$ and Lily Stojanovska* \\ ${ }^{1}$ School of Biomedical and Health Sciences, Victoria University, St Albans Campus, PO Box 14428, Melbourne, VIC 8001, \\ Australia \\ ${ }^{2}$ Clinical Nutrition and Metabolism Unit, Monash University Department of Medicine, Monash Medical Centre, Clayton, \\ VIC 3168, Australia \\ ${ }^{3}$ Department of Nutrition and Dietetics, Monash University, Clayton, VIC 3168, Australia \\ ${ }^{4}$ Sanitarium Development and Innovation, Cooranbong, NSW 2265, Australia
}

(Received 15 April 2010 - Revised 27 July 2010 - Accepted 1 August 2010 - First published online 21 September 2010)

\begin{abstract}
Ageing women may choose to drink soya milk to reduce menopausal symptoms. As fermentation enriches soya milk with isoflavone aglycones, its beneficial qualities may improve. To reduce osteoporotic risk, however, soya milk must be Ca enriched, and it is not known how fermentation affects Ca bioavailability. A randomised crossover pilot study was undertaken to compare the Ca absorption of fortified soya milk with that of fermented and fortified soya milk in twelve Australian osteopenic post-menopausal women. The fortified soya milk was inoculated with Lactobacillus acidophilus American Type Culture Collection (ATCC) 4962 and fermented for $24 \mathrm{~h}$ at $37^{\circ} \mathrm{C}$. Ca absorption from soya milk samples was measured using a single isotope radiocalcium method. Participants had a mean age of $54 \cdot 8$ (SD 12.3) years, with mean BMI of 26.5 (SD 5.5$) \mathrm{kg} / \mathrm{m}^{2}$ and subnormal to normal serum 25-hydroxyvitamin D (mean 62.5 (SD 19.1) nmol/1). Participants consumed $185 \mathrm{kBq}$ of ${ }^{45} \mathrm{Ca}$ in $44 \mathrm{mg}$ of $\mathrm{Ca}$ carrier. The mean fractional Ca absorption $(\alpha)$ from soya milk and fermented soya milk was 0.64 (SD 0.23 ) and 0.71 (SD 0.29$)$, respectively, a difference not of statistical significance $(P=0 \cdot 122)$. Although fermentation of soya milk may provide other health benefits, fermentation had little effect on acute Ca absorption.
\end{abstract}

Key words: Calcium: Soya milk: Fermentation: Post-menopausal women

Soya milk, as a protein-rich drink containing isoflavones, is increasingly consumed in developed countries. Potential benefits include relief from hot flushes, improved lipid profiles, protection against oxidative damage to DNA and, in particular, maintenance of bone health ${ }^{(1-3)}$. Long-term consumption of isoflavones can have bone-sparing effects due to attenuation of bone loss ${ }^{(3,4)}$. Little is known on whether fermentation of soya milk will also affect $\mathrm{Ca}$ absorption from the small intestine.

Natural soya milk contains approximately $20 \mathrm{mg} \mathrm{Ca} / 100 \mathrm{ml}$ compared with cows' milk which contains approximately $120 \mathrm{mg} \mathrm{Ca} / 100 \mathrm{ml}$. Commercially available soya milk is now fortified to the same level as cows' milk by adding fortificants such as calcium phosphate or carbonate. Not all $\mathrm{Ca}$ fortificants, however, are equivalent ${ }^{(5)}$. The bioavailability rather than the total content of $\mathrm{Ca}$ in soya milk is thus an important issue. Ca bioavailability is improved by the presence of high amounts of soluble $\mathrm{Ca}$ in food ${ }^{(6,7)}$ and by facilitating ionisation of $\mathrm{Ca}$ in the digestive system.

One way to potentially enhance the biological activity and nutritional value of soya milk is through fermentation with probiotics. The fermentation of soya milk in vitro with $\beta$-glucosidase-producing probiotic bacterial strains allows acetyl-glucoside and $\beta$-glucoside isoflavones to undergo enzymatic hydrolysis into biologically available aglycone structures and also increases Ca solubility ${ }^{(8)}$. Aglycones are absorbed faster and in greater amounts than their corresponding glucosides ${ }^{(9,10)}$.

In addition, probiotics are a living microbial food supplement which may have beneficial effects on symptoms of lactose intolerance, atopic disorders and coeliac disease, and they are useful in the treatment of diarrhoea, ulcerative colitis and irritable bowel syndrome ${ }^{(11)}$. Claims are also

Abbreviations: ATCC, American Type Culture Collection; CFSM, Ca-fortified soya milk. 
made for cholesterol-lowering effects, anti-carcinogenic actions and improved immune function ${ }^{(12)}$.

Our hypothesis is that fermented soya milk may have greater $\mathrm{Ca}$ bioavailability as measured by fractional $\mathrm{Ca}$ absorption than an otherwise equivalent non-fermented soya milk.

Post-menopausal women are at high risk of osteoporosis following increased bone loss. In the present study, we have investigated whether fermentation of fortified soya milk improves hourly fractional $\mathrm{Ca}$ absorption. A wellestablished crossover radioisotope method was used to compare $\mathrm{Ca}$ absorption from Ca-fortified soya milk $v$. fermented Ca-fortified soya milk in osteopenic but otherwise healthy Australian post-menopausal women.

\section{Experimental methods}

\section{Calcium fortification of soya milk}

The Ca-fortified soya milk (CFSM) used in the present study is widely sold throughout Australia (So Good; Sanitarium Health Foods, NSW, Australia). It is made from soya protein isolate (4\%) and has been fortified with a 'proprietary' phosphate of Ca to achieve Ca content similar to that of cows' milk $(120 \mathrm{mg} / 100 \mathrm{ml})$.

\section{Labelling of the fortificant with ${ }^{45} \mathrm{Ca}$ after soya milk manufacture}

The fortificant present in the CFSM was labelled by adding $1 \mu \mathrm{g}$ of high-specific activity ${ }^{45} \mathrm{CaCl}_{2}$ to a $20 \mathrm{ml}$ amount of soya milk, yielding a tracer concentration of approximately $185 \mathrm{kBq}$. Labelled CFSM was vortexed continuously for $1 \mathrm{~min}$ and then heat-treated $\left(90^{\circ} \mathrm{C}\right.$ for $\left.30 \mathrm{~min}\right)$ before storing at $4^{\circ} \mathrm{C}$ for $24 \mathrm{~h}$ to allow for Ca exchange. The labelled CFSM was then either given after the $24 \mathrm{~h}$ exchange as the test drink or fermented before consumption with Lactobacillus acidophilus American Type Culture Collection (ATCC) 4962.

\section{Bacteria}

A pure culture of $L$. acidophilus ATCC 4962 was obtained from the Victoria University Culture Collection (Werribee, VIC, Australia). Purity was checked by Gram staining before storage at $-80^{\circ} \mathrm{C}$ in $40 \%$ glycerol.

\section{Fermentation of calcium-fortified soya milk}

The probiotic culture L. acidophilus ATCC 4962 was activated through three successive transfers in de Man Rogosa Sharpe broth ${ }^{(13)}$ at $37^{\circ} \mathrm{C}$ for $20 \mathrm{~h}$ using a $2 \%$ inoculum. The labelled CFSM was aseptically inoculated with a $1 \%(\mathrm{v} / \mathrm{v})$ inoculum, incubated at $37^{\circ} \mathrm{C}$ for $24 \mathrm{~h}$ and stored for a maximum period of $48 \mathrm{~h}$ at $4^{\circ} \mathrm{C}$ before consumption.

\section{Human study protocol}

Twelve osteopenic but otherwise healthy post-menopausal women aged 50-68 years were recruited by advertisement and screened by telephone interview. Women were included if they were post-menopausal non-smokers diagnosed as osteopenic (i.e. with bone mineral density $T$-score -1 to -2.5 as measured by dual-energy X-ray absorptiometry); were otherwise healthy (no chronic disease by self-report; including gastrointestinal, kidney, liver, parathyroid or CVD); were not taking medications or antibiotics affecting $\mathrm{Ca}$ absorption; and had not taken hormone replacement therapy during the preceding 12 months. The participants were required to be lactose tolerant and not allergic to soya. Each completed an eating habit questionnaire (extracted from a FFQ; Australian Cancer Council, VIC, Australia) to assess dietary $\mathrm{Ca}$ intake. They were asked to avoid any $\mathrm{Ca}$ supplements for at least 4 weeks before and during the study. The present study was conducted according to the guidelines of the 1995 Declaration of Helsinki as revised in Edinburgh, 2000, and all procedures were approved by the Southern Health Human Research and Ethics Committee (project number 07013A). Written informed consent was obtained from all the participants.

\section{Test milk drinks for the acute pilot study}

Soya milk for the acute study had a tracer concentration of $185 \mathrm{kBq} /$ dose. Each dose comprises $20 \mathrm{ml}$ of the test drink containing a microgram amount of ${ }^{45} \mathrm{CaCl}_{2}$ (Amersham Biosciences, Rydalmere, NSW, Australia) in a total $44 \mathrm{mg}$ of Ca carrier $\left(20 \mathrm{mg}\right.$ as ${ }^{45} \mathrm{Ca}$ and $24 \mathrm{mg}$ as ${ }^{40} \mathrm{Ca}$ present in the CFSM). Immediately after ingestion of the test soya milk, $200 \mathrm{ml}$ of distilled water was consumed.

\section{Study design}

The participants arrived at Monash Medical Centre after an overnight fast and were tested for $\mathrm{Ca}$ absorption on two separate occasions. Treatments were randomised and given in a crossover design study with a minimum washout between tests of 3 weeks. At each test, the subjects consumed either radiolabelled CFSM or radiolabelled and fermented CFSM. At each visit, bioelectrical impedance was determined (SFB7; Impedimed, Brisbane, QLD, Australia). A $10 \mathrm{ml}$ venous blood sample was collected from an antecubital vein for a baseline sample and for measurement of serum 25-hydroxyvitamin D. Participants then consumed the $20 \mathrm{ml}$ test drink immediately followed by the consumption of $200 \mathrm{ml}$ distilled water. Blood samples were collected after $60 \mathrm{~min}$ as described by Nordin et $a l^{(14)}$. These were centrifuged at $3500 \mathrm{~g}$ for $10 \mathrm{~min}$, and the activity of ${ }^{45} \mathrm{Ca}$ in $1 \mathrm{ml}$ plasma aliquots was measured using a liquid scintillation counter (Wallac 1410; Perkin Elmer Life Sciences, MA, USA). Fractional $\mathrm{Ca}(\alpha)$ was then calculated ${ }^{(15)}$ 


\section{Calculation and statistical analysis}

The sample of twelve women recruited into this crossover design pilot study provides a probability of $90 \%$ that a treatment difference can be detected at the $5 \%$ level of significance (two sided), if the true difference between the treatments is $15 \%$. This calculation is based on the assumption that the within-patient SD of the response variable is $10 \%$. Data from the present study were compared by Student's paired $t$ test. SPSS for Windows (version 11.5; SPSS Australasia Limited, Melbourne, VIC, Australia) was used for statistical analyses. A $P$ value of $<0.05$ was considered as significant.

\section{Results}

\section{Comparison of calcium absorption from calcium-fortified soya milk v. fermented calcium-fortified soya milk}

Women in the study had a mean age of 54.8 (SD 12.3 ) years and were overweight (mean BMI 26.5 (SD 5.5) kg/m²). Mean serum 25-hydroxyvitamin D was $62 \cdot 6$ (SD 19.1) nmol/1 (range 31-96 nmol/1). Most women had normal levels, but 38.5\% women had vitamin D insufficiency (serum 25-hydroxyvitamin $\mathrm{D}<50 \mathrm{nmol} / \mathrm{l}$ ).

The mean fractional $\mathrm{Ca}$ absorption $(\alpha)$ values for fermented CFSM compared to CFSM were 0.71 (SD 0.29) and 0.64 (SD 0.23), respectively. The mean fractional $\mathrm{Ca}$ absorption ( $\alpha$ ) of the fermented CFSM was approximately $10 \%$ higher compared with that of CFSM, a difference not of statistical significance $(P=0 \cdot 122)$. The individual differences in fractional $\mathrm{Ca}$ absorption between fortified soya milk and fermented fortified soya milk in the participants are shown in Fig. 1.

\section{Discussion}

In vitro studies indicate that fermentation of soya milk with some probiotics may enhance Ca solubility and bioavailability $^{(8,16)}$. To date, no other studies have examined the

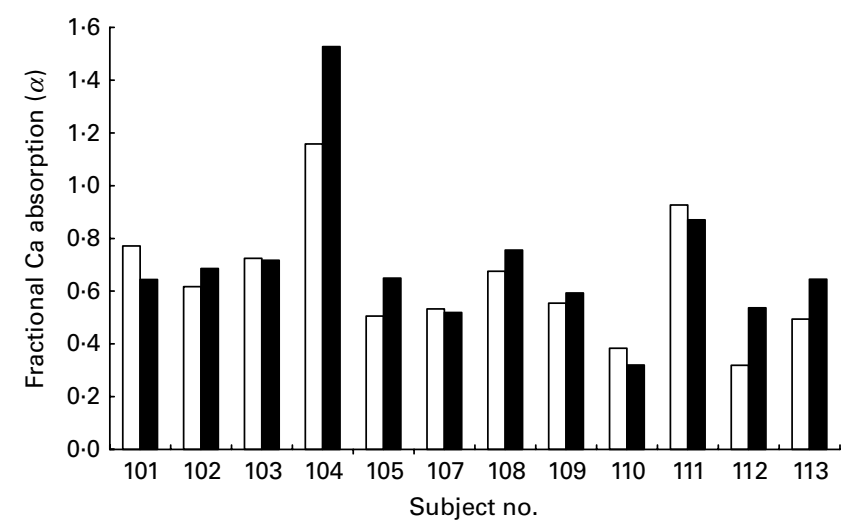

Fig. 1. Fractional $\mathrm{Ca}$ absorption from calcium-fortified soya milk ( $\square$ ) and fermented Ca-fortified soya milk (ם) in twelve individual osteopenic postmenopausal women. effects of fermenting CFSM on Ca absorption in human subjects. In the present study, the participants were not vegetarian, and most of them (77\%) rarely consumed soya milk or soya products. Around one-third (38.5\%) of them regularly had $\mathrm{Ca}$ and vitamin $\mathrm{D}$ supplements. All performed only low to moderate physical activity. Habitual intake of $\mathrm{Ca}$ (by self-report) was moderate, and $\mathrm{Ca}$ supplementation was avoided during the study. Ca intake by the participants is, thus, unlikely to have affected the present results; moreover, from the crossover design of the study, each participant acted as their own control.

The study was based on the single isotope radiocalcium absorption test, a robust, well-validated measure of $\mathrm{Ca}$ absorption $^{(14)}$. This method would be applicable to other drinks fortified with $\mathrm{Ca}$. The test can be completed over a short-time period, allowing absorption from a segment of small intestine to be followed via a sharp peak of radioactivity $^{(17)}$. The rate of $\mathrm{Ca}$ absorption measured by this method correlates strongly with that measured in balance studies and correlates very highly with double isotope Ca absorption tests ${ }^{(18)}$. It is important, however, when employing this method, to use a small Ca load (e.g. $44 \mathrm{mg}$ as here). Higher loads increase absorption time and will reduce test sensitivity. The larger the carrier dose, the more interference during the $\mathrm{Ca}$ absorption diffusion process and the less valid the single-isotope procedure ${ }^{(14)}$. The labelling of the fortificant with ${ }^{45} \mathrm{Ca}$ after soya milk manufacture was shown to have a tracer distribution pattern very similar to that when the fortificant was labelled before the soya milk manufacture, provided a heat treatment was applied ${ }^{(19)}$. In the present study, the soya milk fortificant was also labelled before the fermentation. No studies have indicated negative effects of probiotics on the availability of the ${ }^{45} \mathrm{Ca}$ radioisotope during Ca absorption, although a recent study found that $\mathrm{Ca}^{2+}$ plays a positive catalytic role for human gut colonic bacteria $^{(20)}$.

We have shown that fermenting CFSM with L. acidophilus ATCC 4962 did not improve fractional Ca absorption in twelve osteopenic post-menopausal women. The insignificant effect of fermentation on $\mathrm{Ca}$ bioavailability observed may in part reflect our choice of CFSM for fermentation. We have previously demonstrated that the fractional $\mathrm{Ca}$ absorption ( $\alpha$ ) from the CFSM used in the present study is comparable to that of cows' milk ${ }^{(19)}$. The fortificant present in this CFSM may already be in its most absorbable form so that fermentation in this case does not significantly improve acute $\mathrm{Ca}$ absorption. Optimum Ca absorption ( $\alpha$ ) was observed $1 \mathrm{~h}$ after ingestion of the unfermented soya milk. It remains possible that fermentation will improve $\mathrm{Ca}$ absorption in other soya milk drinks where other methods of Ca fortification have been used. It would thus be valuable to repeat the present study with other types of commercially available fortified soya milk. 
Even without change in Ca bioavailability, fermentation may have health benefits as it significantly increases aglycone content (increasing daidzein, glycitein and genistein $)^{(8)}$. Fermentation also increases the solubility of Ca by decreasing soya milk pH. Moreover, the phytase enzyme produced by some probiotics will hydrolyse phytic acid and IP6-generating myo-inositols with reduced numbers of phosphate groups (IP3-IP5) ${ }^{(21,22)}$ causing a beneficial effect on $\mathrm{Ca}$ bioavailability. In the present study, the CFSM was made from soya protein isolate rather than from a whole soya bean, and even before fermentation, it had minimal phytic acid content.

Fig. 1 shows the individual fractional $\mathrm{Ca}$ absorption from CFSM to fermented CFSM. Four of the twelve postmenopausal women absorbed $\mathrm{Ca}$ from the fermented CFSM better than from the non-fermented CFSM (32, 28, 69 and 31\%, respectively). These women may have come from the approximate one-third of the population who are 'equol producers', a mechanism known to facilitate $\mathrm{Ca}$ absorption ${ }^{(23)}$. In further studies, it would be advised to assess equol-producing status via $24 \mathrm{~h}$ urine excretion ${ }^{(23)}$. Although our acute study indicates that fermentation of CFSM has no effect on Ca bioavailability under conditions of acute absorption from the small intestine, it cannot rule out the possibility that fermented CFSM facillitates slower $\mathrm{Ca}$ absorption from the large intestine. Post hoc analysis suggests that for adequate statistical power, 174 subjects would be needed for the present study per treatment group. Our pilot study may thus have been underpowered to detect any small difference in bioavailability between the two test drinks. It does not exclude a greater difference with fermentation in different soya milk drinks fortified by other methods. Our findings do not therefore preclude possible benefits on long-term consumption of fermented CFSM on bone health and $\mathrm{Ca}$ balance.

In summary, during this acute pilot study, there was no significant improvement on fractional $\mathrm{Ca}$ absorption from the ingestion of CFSM fermented with L. acidophilus ATCC 4962 in osteopenic post-menopausal women. Limitations of this randomised crossover pilot study include the sample size of twelve, the use of a test soya milk with relatively high Ca bioavailability in its non-fermented state and the comparison of small-intestinal $\mathrm{Ca}$ absorption in the acute setting only, therefore looking at neither differences in colonic $\mathrm{Ca}$ absorption nor longer-term $\mathrm{Ca}$ accretion with the two test soya milk drinks. To observe a significant improvement in fractional $\mathrm{Ca}$ absorption with this particular brand of soya milk, a much larger sample size study would be required. The effects of fermentation might be observed more readily with soya milk of different composition (e.g. whole bean rather than soya protein isolate based) and $\mathrm{Ca}$ fortification system. Fermentation of CFSM may also contribute to the potential cumulative long-term benefits on $\mathrm{Ca}$ bioavailability and bone health. A longer-term study, over at least 6-12 months, looking at markers of bone turnover and bone mineral densitometry, may be needed to test this hypothesis further.

\section{Acknowledgements}

We thank members of the Department of Nuclear Medicine, the Body Composition Laboratory from the Monash Medical Centre and the Department of Medicine, Monash University, Victoria, Australia, for their kind support. The present study was supported by the Sanitarium Health Food Company from the Australian Research Council Sanitarium linkage grant funding. A. L. T. F. C. contributed to the overall study from experimental design, collection and analysing of data to writing of the manuscript; G. W., K. Z. W., N. P. S., J. F. A., B. S. and L. S. conceived the idea, designed the experiment and helped with data interpretation and editing of the manuscript; J. F. A. is currently employed by the Sanitarium Health Food Company, Australia. The sponsors of the study and the authors had no conflict of interest.

\section{References}

1. Lydeking-Olsen E, Beck-Jensen JE, Setchell KDR, et al. (2004) Soymilk or progesterone for prevention of bone loss. Eur J Nutr 43, 246-257.

2. Setchell KDR \& Lydeking-Olsen E (2003) Dietary phytoestrogen and their effect on bone: evidence from in vitro and in vivo observational, and dietary intervention studies. Am J Clin Nutr 78, Suppl. 3, 593S-609S.

3. Atkinson C, Compston JE, Day NE, et al. (2004) The effects of phytoestrogen isoflavones on bone density in women: a double blind, randomized, placebo-controlled trial. Am J Clin Nutr 79, 326-333.

4. Chen YM, Ho SC, Lam SSH, et al. (2003) Soy isoflavones have a favorable effect on bone loss in Chinese postmenopausal women with lower bone mass: a double-blind, randomized, controlled trial. J Clin Endocrinol Metab 88, $4740-4747$.

5. Heaney RP, Rafferty K \& Bierman J (2005) Not all calciumfortified beverages are equal. Nutr Today 40, 39-44.

6. Schroder BG, Griffin IJ, Specker BL, et al. (2005) Absorption of calcium from the carbonated dairy soft drink is greater than that from fat-free milk and calcium-fortified orange juice in women. Nutr Res 25, 737-742.

7. Theobald HE (2005) Dietary calcium and health. Nutr Bull 30, 237-277.

8. Tang AL, Shah NP, Wilcox G, et al. (2007) Fermentation of calcium-fortified soymilk with lactobacillus: effects on calcium solubility, isoflavone conversion, and production of organic acids. J Food Sci 72, 431-436.

9. Izumi T, Piskula MK, Osawa S, et al. (2000) Soy isoflavone aglycones are absorbed faster and in higher amounts than their glucosides in humans. J Nutr 130, 1695-1699.

10. Kano M, Takayanagi T, Harada K, et al. (2006) Bioavailability of isoflavones after ingestion of soy beverages in healthy adults. J Nutr 136, 2291-2296.

11. Gibson GR, Rastall RA \& Fiuller R (2003) The health benefits of probiotics and prebiotics. In Gut Flora, Nutrition, 
Immunity and Health, pp. 52-69 [R Fuller and G Perdigon, editors]. Oxford: Blackwell Publishing Ltd.

12. Tannock GW (2005) Probiotics and Prebiotics: Scientific Aspects. Norfolk: Caister Academic Press.

13. De Mann JD, Rogosa M \& Sharpe ME (1960) A medium for the cultivation of lactobacilli. I Appl Bacteriol 23, $130-135$.

14. Nordin BEC, Morris HA, Wishart JM, et al. (1998) Modification and validation of a single-isotope radiocalcium absorption test. $J$ Nucl Med 39, 108-113.

15. Marshall DH \& Nordin BEC (1981) A comparison of radioactive calcium absorption tests with net calcium absorption. Clin Sci 61, 477-481.

16. Tsangalis D, Ashton JF, Stojanovska L, et al. (2004) Development of an isoflavone aglycone-enriched soymilk using soy germ, soy protein and bifidobacteria. Food Res Int 37, 301-312.

17. Nordin BEC (1976) Calcium, Phosphate and Magnesium Metabolism: Clinical Physiology and Diagnostic Procedures. London: Churchill Livingstone.
18. Nordin BEC, Morris HA, Horowitz M, et al. (2009) Calcium malabsorption does not cause secondary hyperparathyroidism. Calcif Tissue Int 85, 31-36.

19. Tang AL, Walker KZ, Wilcox G, et al. (2010) Calcium absorption in Australian osteopenic post-menopausal women: an acute comparative study of fortified soymilk to cows' milk. Asia Pac J Clin Nutr 19, 243-249.

20. Zhu Y, Suits MDL, Thompson AJ, et al. (2010) Mechanistic insights into a $\mathrm{Ca}^{2+}$-dependent family of $\alpha$ mannosidases in a human gut symbiont. Nat Chem Biol 6, 125-132.

21. Haros M, Bielecka M \& Sanz Y (2005) Phytase activity as a novel metabolic feature in Bifidobacterium. FEMS Microbiol Lett 247, 231-239.

22. Haros M, Carlsson NG, Almgren A, et al. (2009) Phytate degradation by human gut isolated Bifidobacterium pseudocatenulatum ATCC27919 and its probiotics potential. Int J Food Microbiol 135, 7-14.

23. Setchell KDR \& Cole SJ (2006) Method of defining equolproducer status and its frequency among vegeterians. J Nutr 136, 2188-2193. 